\title{
Organocatalytic Asymmetric Michael Addition of $\beta$-Ketoesters to Nitroalkenes
}

\author{
Bo Kyung Kwon and Dae Young Kim* \\ Department of Chemistry, Soonchumbang Linversity, Asan, Chungnam 336-745, Korea. 'E-mail: dioungaschack \\ Received April 23. 2009. Accepted Jine 4, 2009
}

Key Words: Bifunctional organocatalỵsts. Michael addition. Aș̣'mmetric reactions. $\beta$-Ketoesters. Nitroalkenes

The Michael addition reaction is widely recognized as one of the most general and versatile methods for formation of $\mathrm{C}-\mathrm{C}$ bonds in organic syththesis. ${ }^{3}$ and the development of enantioselective catalytic protocols for this reaction has been subject of intensive research. ${ }^{-}$In addition to the great success catalyzed by metal complexes, the powerful and environmentally friendly organocatalyst-mediated ast mmetric Michael reaction has been explored intensively in recent years. ${ }^{3+4}$ Michael reaction of nucleophiles to nitroalkenes represents a direct and most appealing approach to chiral nitroalkanes that are versatile intermediates in organic synthesis, which can be transformed into an amine. nitrile oxide. ketone carboxylic acid. hydrogen etc. ${ }^{5}$ The conjugate addition of $\alpha$-substituted dicarbonyl compounds to suitable acceptor represents an important approach to generate all-carbon quaternary stereogenic centers. Takemoto et al. applied their bifunctional thiourea cataly̧st in așymmetric Michael addition of $\beta$ ketoester compounds to nitroolefins. ${ }^{6}$ Also, Deng ef al. reported the constniction of quatemary stereogenic centers by conjugate addition of $\beta$-ketoesters mediated by cinchona alkaloid catalyst.

As part of research program related to the development of synthetic methods for the enantioselective construction of

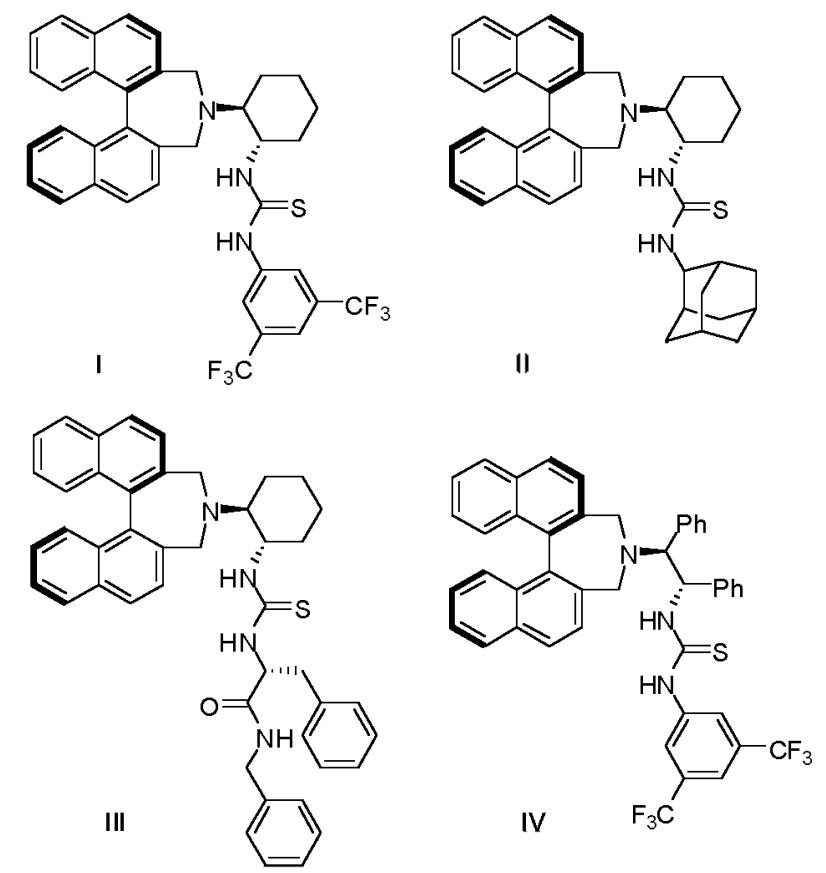

Figure 1. Structure of chiral thiourea-tertiary amine catalysts. stereogenic carbon centers. ${ }^{3}$ we recently reported chiral aninethiourea I (Fig. 1) to be a highly selective catalyst for the enantioselective amination of active methines. ${ }^{9}$ We envision that the rigid binaphthyl structure can serve as an efficient stereocontrolling axial chiral element. Herein. we wish to describe the direct asymmetric Michael reaction of $\beta$-ketoesters to nitroalkenes with catalyzed by bifunctional organocatalysts bearing both central and axial chiral elements.

A survey of some reaction parameters was performed and some representative results are presented in Table 1. Our investigation began with the catalytic asymmetric Michael addition of methyl cyclopentanone 2-carboxylate (1a) with nitrostyrene (2a). When the reaction was performed in toluene at room temperature in the presence of $10 \mathrm{~mol} \%$ catalyst $\mathbf{L}$ product 3 a was isolated in high yield with $85 \%$ ee (Table 1 , entry 1). We first exanuined the impact of the structure of catalysts I-IV on enantioselectivity (Table 1. 60-85\% ee. entries 1-4). The best results have been obtained with catalysts I and IV. Concerning the solvent (entries 1, 5-7), the use of halogenated solvents. especially. dibromonethane gave the best result in the yield and the enantiomeric excess (>99\% ee. entry 6).

We then explored the possibility of using wide range of para-substituted aromatic and heteroaromatic nitroalkenes 2 with $\beta$-ketoester la under the optinuzed reaction condition.

Table 1. Optimazation of the reaction conditions
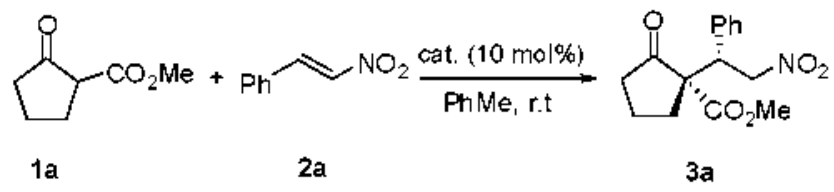

\begin{tabular}{cccccc}
\hline entry & cat. & $\begin{array}{c}\text { time } \\
(\mathbf{h})\end{array}$ & $\begin{array}{c}\text { yield }^{a} \\
(\%)\end{array}$ & $\begin{array}{c}\mathrm{dr}^{b} \\
(\text { smianti })\end{array}$ & $\begin{array}{c}\mathrm{ee}^{c} \\
(\%)\end{array}$ \\
\hline 1 & I & 12 & 95 & $85: 15$ & 85 \\
2 & II & 32 & 93 & $90: 10$ & 73 \\
3 & III & 48 & 92 & $77: 23$ & 60 \\
4 & IV & 120 & 90 & $94: 6$ & 83 \\
$5^{d}$ & I & 6 & 95 & $86: 14$ & 91 \\
$6^{\circ}$ & I & 4 & 98 & $86: 14$ & $>99$ \\
$7^{\prime}$ & I & 10 & 93 & $85: 15$ & 89 \\
\hline
\end{tabular}

"Refers to the isolated mixture of diastereomers. ${ }^{b}$ Determined from crude ${ }^{1} \mathrm{H}$ NMR spectra. 'Enantiomeric excess of the major isomer, determined by chiral HPLC analysis. "The reaction was run in $\mathrm{CH}_{2} \mathrm{Cl}_{2}$ as soltent. "The reaction was run in $\mathrm{CH}_{2} \mathrm{Br}$; as solvent. "The reaction was run in $\mathrm{CHCl}_{3}$ as solvent. 
Table 2. Variation of the nitroalkene

\begin{tabular}{|c|c|c|c|c|c|}
\hline $1 \mathrm{a}$ & 2 & & & 3 & \\
\hline entry & $2, \mathrm{Ar}$ & $\begin{array}{c}\text { time } \\
\text { (h) }\end{array}$ & $\begin{array}{c}\text { yield } \\
(\%)\end{array}$ & $\begin{array}{c}\mathrm{dr}^{b} \\
(\operatorname{sth} a n t i)\end{array}$ & $\begin{array}{l}\mathrm{ee}^{\mathrm{c}} \\
(\%)\end{array}$ \\
\hline 1 & 2a. Ph & 4 & 3a 98 & $86: 14$ & $>99$ \\
\hline 2 & 2b, p-F-Pli & 3 & $3 b, 96$ & $86: 14$ & 93 \\
\hline 3 & 2c, $p-\mathrm{Cl}-\mathrm{Ph}$ & 3 & $3 c, 97$ & $84: 16$ & 95 \\
\hline $4^{l}$ & 2d, $p$-Me-Ph & 36 & $3 d, 91$ & $85: 15$ & 91 \\
\hline 5 & 2e, $p$-MeO-Ph & 18 & $3 e, 90$ & $82: 18$ & 88 \\
\hline
\end{tabular}

"Refers to the isolated misture of diastereomers. ${ }^{b}$ Detemined from crude ${ }^{1} \mathrm{H} N M R$ spectra. 'Enantiomeric excess of the major isomer, deternined by chiral HPLC analysis. "This reaction was carried out at $-40^{\circ} \mathrm{C}$.

Table 3. Variation of the $\beta$-ketoester

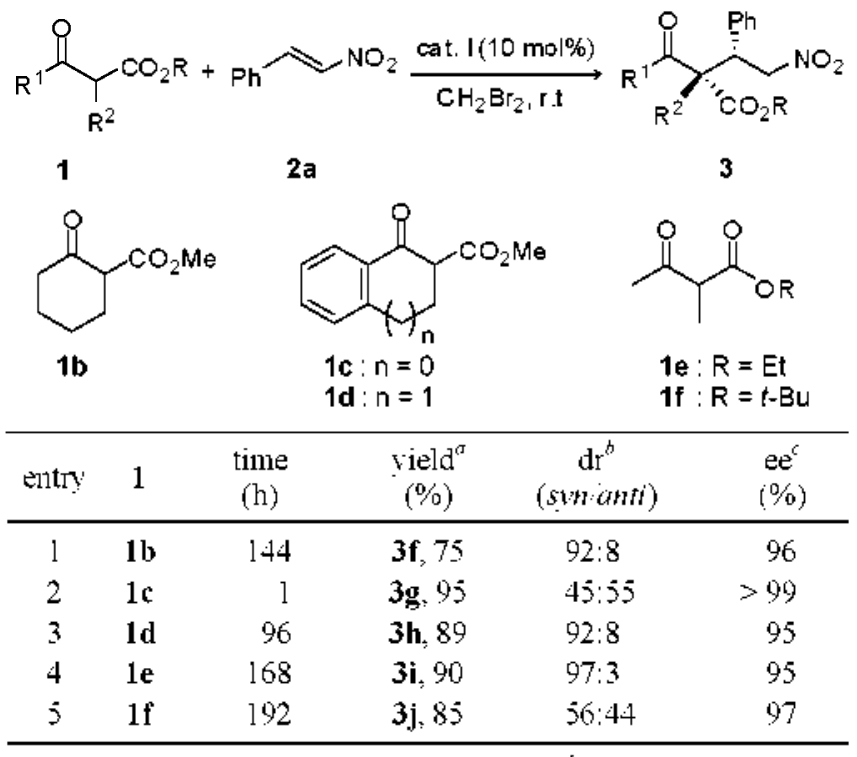

${ }^{a}$ Refers to the isolated mixture of diastereomers. ${ }^{b}$ Determined from crude 'H NMR spectra. 'Enantioneric excess of the major isomer, determined by chiral HPLC analysis.

As shown in Table 2 . the products 3a-e were formed in high yields $(90-98 \%$ ). high diastereoselectivities. and excellent enatioselectivities ( 88 - > $99 \%$ ).

To examine the generality of the catalytic asymmetric Michael reaction of $\beta$-ketoesters 1 by using new bifunctional organocatalyst $\mathbf{I}$ we studied the addition of various $\beta$ ketoesters 1 to nitrosty rene (2a). As it can be seen by the results summarized in Table 3 . the corresponding products 3f-j were obtained in high to excellent yields. high diastereoselectivities, and excellent enantioselectivities. The absolute configuration of adducts 3 has been determined for some derivatives by comparison of their optical and HPLC properties with literature values.

In conclusion, we have developed a highly efficient catalytic asymmetric Michael reaction of $\beta$-ketoesters to nitroalkenes using bifunctional organocatalyst I. The desired $\gamma$-nitro carbonyl compounds were obtained in good to ligh yields, excellent diastereoselectivities (up to 86:14), and excellent enantioselectivities (up to $>99 \%$ ee) were observed. Further study of these bifunctional organocatalysts in asymmetric reactions is being under investigation.

\section{Refeiences}

1. Perlmutter, P. Conjugate Addition Reactions in Organic Symthesis; Pergamon: Oxford, 1992.

2. For recent reviews of asymmetric Michael addition reactions. see: (a) Bemer, O. M:; Tedeschi, L.: Enders, D. Em. J. Org. Chem. 2002, 1877. (b) Christoffers, T, Baro, A. Angew'. Chem. Int. Ed. 2003, 42,1688 .

3. For selected recent reviews for bifunctional organocatalysts, See: (a) Connon, S. I. Sinlett 2009, 354, (b) Yu, X.: Wang. W. Chem. Asian J. 2008, 3,516. (c) Doyle, A. G.: Tacobsen, E. N. Chent. Rev. 2007, 107,5713.

4. For recent reviews of organocatalytic asymmetric Michael addition, see: (a) Tsogoeva, S. B. Eur. J. Org. Chem. 2007, 1701. (b) Almasi, D: Alonso, D. A.; Najera, D. Tetrahedron . Asmmetr, $2007,18,299$.

5. (a) Ono, N. The Nitro Group in Onganic Synthesis; Wiley-VCH: New York, 2001. (b) Ballini, R.: Petrini, M. Tetrahedron 2004. 60. 1017. (c) Czekelius, C.: Carreira, E. M. Angew. Chem. Int. Ed. 2005, 4t.612

6. Okino, T.; Hoashi, Y.: Furukawa, T.; Xu, X.: Takemoto, Y. J. Ant Chem. Soc. 2005, 127, 119

7. (a) Li, H.; Wang, Y.; Tang, L.; Wu, F.: Lin, X.: Guo, C.; Foxman, B. M; Deng, L.Angew. Chem. Int Ed 2005, Ht, 105 (b) Wu, F.; Li, H.; Hong, R.; Deng, L. Angew. Chent. Int Ed. 2006, 45, 947.

8. (a) Mang. I. Y.; Kwon. D. G.: Kim. D. Y. J. Fluorine Chem. $2009,130,259$ (b) Lee, N. R.; Kim, S. M. Kim, D. Y. Bull. Korean Chem. Soc. 2009, 30, 829 (c) Mang, T. Y.; Kwon, D. G.; Kim, D. Y. Bull Korean Chem. Soc. 2009, 30, 249. (d) Kim, D. Y. Bull. Korean Chem. Soc. 2008, 29, 2036. (e) Kang, Y. K.; Kim. D. Y. Bull. Korean Chem. Soc. 2008, 29, 2093. (f) Lee, I. H.; Bang, H. T.; Kim, D. Y. Synlen 2008, 1821 . (g) Kang, Y. K; Cho, M. J.: Kim, S. M.; Kim, D. Y. Synlett 2007, 1135. (h) Kim, S. M.; Kang, Y. K.; Cho, M. J.; Kim, D. Y. Bull Korean Chen. Soc. 2007, 28, 2435. (i) Cho, M. T; Kang, Y. K : Lee, N. R; Kim, D. Y. Bull Korean Chem. Soc 2007, 28, 2191. (j) Kim, S. M.; Kang. Y. K.; Lee, K.; Mang, I. Y.; Kim, D. Y. Bull. Konean Chem. Soc. 2006. 27.423. (k) Kang. Y. K.: Kim. D. Y. Tetrahedron Lett. 2006, 47, 4265. (1) Kim, H. R.; Kim, D. Y. Tetrahedron Lett. 2005, 46, 3115 . (m) Kim, S. M.; Kim, H. R.; Kim, D. Y. Org. Lett. 2005, 7, 2309. (n) Park, E. J.: Kim, M. H.: Kim, D. Y. J. Org. Chem 2004, 69, 6897. (o) Kim, D. Y: Park, E. T. Org. Letr. $2002,4,545$ (p) Kim. D. Y.: Huh S. C.: Kim S. M Tetrahedron Letr. 2001, 42,6299. (q) Kim, D. Y, Huh, S. C. Tetrahedron 2001. 57,8933 .

9. (a) Kim, S. M.; Lee, J. H.: Kim, D. Y. Smlet 2008, 2659. (b) Jung, S. H.; Kim, D. Y. Tetwahedron Lett. 2008, 19, 5527. (c) Mans. T. Y,; Kim. D. Y. Bull. Korean Chem. Soc. 2008, 29, 2091. 